\title{
Prognostic value of cytokines in breast cancer: Correlation with positive hormonal status and obesity
}

Noha Yehia Ibrahim*, Soha Mohamed Talima1, David Fadl Kaldas,

Hebatallah Kassem², Neemat Kassem²

${ }^{1}$ Clinical Oncology Department (NEMROCK), Kasr Al-Ainy School of Medicine,

Cairo University, Egypt

${ }^{2}$ Clinical pathology, Oncology Department (NEMROCK), Kasr Al-Ainy School

of Medicine, Cairo University, Egypt

Received 3 August 2020; Accepted 29 December 2020

\begin{abstract}
Background: The relation of interleukin 6 (IL6) and molecular subtypes as well as body mass index is not well settled. Little is known about interferon gamma (IF $\gamma$ ) and prognosis of breast cancer.

Patients and methods: Serum level of IL6 and IF $\gamma$ was assessed by enzyme-linked immunosorbent assay (ELISA) and correlated with the TNM staging, molecular subtypes, and body mass index.

Results: Among 78 patients, the median age was 54 years. The majority of the cases were T2 (62.8\%), N1 (38.5\%), and M0 (89.74\%) with stage II being the most common (47.4\%). Most females were estrogen receptor (97.9\%) and progesterone receptor positive (96.9\%) with high Ki67 $\geq 20$ (61.5\%). Her2 neu positive presented $16.7 \%$. Luminal A and luminal B presented $29.5 \%$ and $53.8 \%$, respectively. Obese patients presented by far the majority (82.1\%).

The median level of IL6 and IF $\gamma$ was $56.20 \pm 28.715$ and $76.37 \pm 41.54$, respectively. IL6 was significantly correlated with tumor size $(P=0.001)$, nodal involvement $(P=>0.0001)$, the presence of metastasis $(P=0.008)$, and the stage $(P=>0.0001)$. High level of IL6 was associated with positive estrogen receptor, Her2 neu positive, luminal $A$, and being obese $(P=0.09,0.07,0.06$, and 0.05 , respectively).

High IF $\gamma$ was only associated with lower nodal burden being significantly higher in N1 than in N3 $(118.15 \pm 31.07$ vs $76.37 \pm 44.46$, $P=0.01)$ and early stage $(P=0.02)$.

Conclusions: IL6 level was correlated to the initial staging, hormonal status, being Her2 positive, and obesity. The IF level was inversely correlated IL6 regarding the nodal status $(P=0.05)$.
\end{abstract}

Keywords: cytokine $\bullet I L 6 \bullet I F \gamma ・$ prognosis • breast cancer • epidemiology

\section{Introduction}

Breast cancer is one of the most common cancers in female leading to cancer-related death ${ }^{[1]}$. The course of the disease is affected my many variables including initial TNM staging, hormone receptor status, and Her2 expression $^{[2]}$.

Interleukin 6 (IL6) is a cytokine producing low-grade inflammation inducing cancer. It is also one of the cytokines released in obese patients ${ }^{[3]}$.
IL6 was associated with the TNM staging ${ }^{[4]}$ especially axillary lymph node affection ${ }^{[5,6]}$ and also with the extent and survival in the metastatic setting ${ }^{[7]}$. It was also related to prognosis in triple-negative breast cancer (TNBC) ${ }^{[8]}$.

Interferon gamma (IFY) is a cytokine affecting outcome in breast cancer ${ }^{[9]}$. It has two contradictory effects in cancer cells. It has shown direct anti-tumor activity. However, this cytokine has been also involved in the activation of programmed cell death (PDL1). This leads to protection of the cancer cells from the immune 
attack which ultimately leads to tumor growth. AntiPDL1 may be considered in such patients ${ }^{[10]}$. High level of IFY may affect the response in estrogen-positive breast cancer ${ }^{[11,12]}$.

Obesity is rising in many countries ${ }^{[13]}$. Adipose tissue is associated with pro-inflammatory cytokines, such as IL6, which may affect the prognosis and response to hormonal treatment ${ }^{[14,15,16]}$. Whereas IFY is not well studied in breast cancer patients, correlation between the two cytokines is of benefit as there are some data on IL6 with only scarce information on IFY in breast cancer.

\section{Patients and methods}

All breast cancer patients with estrogen receptor (ER) positive and or progesterone receptor (PR) positive were recruited prior to chemotherapy and were classified according to body mass index into normal (BMI 18.5$24.9)$, overweight (25-29.9), or obese (BMI $\geq 30$ ). They were also stratified into metastatic and non-metastatic.

The study included only luminal $A$ and luminal $B$ molecular subtypes. Other subtypes including HER2 enriched and basal triple-negative breast cancer (TNBC) were not included.

Luminal A was ER and PR positive with low Ki67 and HER2 negative. Luminal B was ER and PR positive with high Ki67, and HER2 may be negative or positive. HER2 enriched is a high expression of HER2 with negative ER and PR. Basal type is low expression of ER, PR, and HER2 ${ }^{[17,18]}$. Basal type is known as triple-negative breast cancer.

Correlation between different cytokines with the TNM staging, hormonal status, Her2, and disease progression as well as response to treatment will be evaluated.

\section{Methods (ELISA)}

Venous blood sample was drawn from 70 hormone receptor-positive breast cancer patients at the time of diagnosis before the initiation of systemic therapy. This included all stages, metastatic and non-metastatic.

Serum levels of IL-6 were determined with an enzyme-linked immunosorbent assay (ELISA) (R\&D Systems, Minneapolis, MN, USA; Quantikine human IL-6). The detection limit of the assay was $0.7 \mathrm{pg} / \mathrm{ml}$. Within-assay reproducibility has been tested before.

\section{Statistical analysis}

\section{Discussion}

The median level of IL6 was 58.39 and was significantly

All data were statistically studied by descriptive analysis. The level of cytokines was correlated with the different clinico-epidemiological factors. This included the initial TNM staging, hormonal status, Her2 status, and BMI.

Data were statistically described in terms of mean \pm standard deviation ( $\pm S D$ ), median, and range, or frequencies (number of cases) and percentages when appropriate. Correlation between various variables was done using Spearman rank correlation equation. $P$ value less than 0.05 was considered statistically significant. All statistical calculations were done using computer program IBM SPSS (Statistical Package for the Social Science; IBM Corp, Armonk, NY, USA) release 22 for Microsoft Windows.

\section{Results}

The clinico-epidemiological characteristics of all 78 breast cancer patients included in the study are shown in Table 1. The median age at diagnosis was 54 years. The majority of the cases were T2 $(62.8 \%)$, N1 (38.5\%), and $\mathrm{MO}(89.74 \%)$ with stage II being the most common (47.4\%). Most females were estrogen receptor (97.9\%) and progesterone receptor positive (96.9\%) with high Ki67 $\geq 20$ (61.5\%). Her2 neu positive presented 16.7\%. Luminal A and luminal B presented $29.5 \%$ and $53.8 \%$, respectively. Patients with triple-negative breast cancer were not included in the study. Concerning the body mass index, obese patients presented by far the majority (82.1\%), and overweight and normal weight constituted only $10.2 \%$ and $7.7 \%$, respectively.

The correlation of IL6 and IFY with various prognostic factor is shown in Table 2. The median serum level IL6 was $56.20 \pm 28.715$, whereas IFY was $76.37 \pm 41.54$. The level of IL6 was significantly correlated with tumor size $(P=0.001)$, nodal involvement $(P=>0.0001)$, and the presence of metastasis $(P=0.008)$. Thereby the stage was affected $(P=>0.0001)$. High level of IL6 was associated with positive estrogen receptor, Her2 neu enriched, luminal $\mathrm{A}$, and being obese $(P=0.09,0.07$, 0.06 , and 0.05 , respectively).

Concerning IFY, a high serum level was only associated with lower nodal burden being significantly higher in $\mathrm{N} 1$ than in $\mathrm{N} 3(118.15 \pm 31.07$ vs $76.37 \pm$ 44.46, $P=0.01)$ and early stage $(P=0.02)$. 
Table 1: Patient characteristics.

\begin{tabular}{|c|c|c|c|}
\hline & Number (78) & $\%$ & P value \\
\hline Median age & $54(29-78)$ & & \\
\hline \multicolumn{4}{|l|}{ Tumor size } \\
\hline T1 & 11 & $14.1 \%$ & $<0.00001$ \\
\hline T2 & 49 & $62.8 \%$ & \\
\hline T3 & 13 & $16.7 \%$ & \\
\hline T4 & 5 & $6.4 \%$ & \\
\hline \multicolumn{4}{|l|}{ Nodal status } \\
\hline No & 27 & $34.6 \%$ & $<0.00001$ \\
\hline N1 & 30 & $38.5 \%$ & \\
\hline N2 & 7 & $9 \%$ & \\
\hline N3 & 14 & $17.9 \%$ & \\
\hline \multicolumn{4}{|l|}{ Metastasis } \\
\hline M1 & 8 & $10.26 \%$ & $<0.00001$ \\
\hline MO & 70 & $89.74 \%$ & \\
\hline \multicolumn{4}{|l|}{ Stage } \\
\hline I & 12 & $15.5 \%$ & $<0.00001$ \\
\hline ॥ & 37 & $47.4 \%$ & \\
\hline III & 26 & $33.3 \%$ & \\
\hline IV & 3 & $3.8 \%$ & \\
\hline \multicolumn{4}{|c|}{ Hormonal status } \\
\hline \multicolumn{4}{|c|}{$\begin{array}{l}\text { Estrogen receptor } \\
\text { (ER) }\end{array}$} \\
\hline Positive & 74 & $94.9 \%$ & $<0.00001$ \\
\hline Negative & 4 & $5.1 \%$ & \\
\hline \multicolumn{4}{|l|}{$\begin{array}{l}\text { Progesterone } \\
\text { receptor (PR) }\end{array}$} \\
\hline Positive & 75 & $96.1 \%$ & $<0.00001$ \\
\hline Negative & 3 & $3.9 \%$ & \\
\hline \multicolumn{4}{|l|}{ Her 2 neu } \\
\hline Positive & 13 & $16.7 \%$ & $<0.00001$ \\
\hline Negative & 65 & $83.3 \%$ & \\
\hline \multicolumn{4}{|l|}{ Ki67 } \\
\hline$>20 \%$ & 48 & $61.5 \%$ & 0.00024 \\
\hline$<20 \%$ & 30 & $38.5 \%$ & \\
\hline \multicolumn{4}{|l|}{ Subtype } \\
\hline Lumina A & 23 & $29.5 \%$ & $<0.00001$ \\
\hline Luminal B & 42 & $53.8 \%$ & \\
\hline Her 2 neu enriched & 13 & $16.7 \%$ & \\
\hline \multicolumn{4}{|c|}{ Body mass index } \\
\hline Normal & 6 & $7.7 \%$ & $<0.00001$ \\
\hline Overweight & 8 & $10.2 \%$ & \\
\hline Obese & 64 & $82.1 \%$ & \\
\hline \multicolumn{4}{|l|}{ Chemotherapy } \\
\hline Yes & 33 & $67.3 \%$ & $<0.00001$ \\
\hline No & 16 & $32.7 \%$ & \\
\hline \multicolumn{4}{|l|}{ Radiotherapy } \\
\hline Yes & 70 & $89.8 \%$ & $<0.00001$ \\
\hline No & 8 & $10.2 \%$ & \\
\hline
\end{tabular}

increased with the tumor size $(P=0.001)$, nodal involvement $(P=>0.0001)$, and the presence of metastasis $(P=0.008)$.

This was in accordance with other study by Saeed et al. (2019) that found the level of IL6 was significantly increased with TNM staging ${ }^{[19]}$.
This result was also consistent with Ravishankaran and Karunanithi (2011), where the level of IL6 was monitored in 59 female breast cancer patients prior to surgery. There was a significantly high level of IL6 with lymph node metastasis and TNM staging, and this was correlated with poor overall survival $(P=0.003)(4)$.

Our results were congruous with the study of Noman et al. (2017), which was done on 110 female breast cancer patients and 30 volunteers. Long-term follow-up of patients showed an association between the elevated IL6 and the risk of bone metastasis as well as early recurrence ${ }^{[20]}$. In a big Chinese study performed on 534 individuals, IL6 was also a poor prognostic marker for disease progression and metastasis ${ }^{[5]}$.

In the present study, elevated level of IL6 was associated with estrogen receptor positive and HER2/ neu enrichment $(P=0.09, P=0.09)$. This was in accordance with Huang et al. (2016), where IL6 in HER2-positive breast cancer leads to drug resistance to lapatinib. IL6 has been proved to be a regulatory cytokine with high level leading to tumor progression ${ }^{[21]}$.

The level of IL6 was increased with high body mass index and was significantly increased in obese breast cancer patients $(P=0.05)$. This is in agreement with other studies ${ }^{[14,15,16]}$.

Inflammation of mammary adipose tissue occurs in overweight and obese patients exhibiting early-stage breast cancer. This was evident in the study by Vaysse et al. (2017) on 107 breast cancer patients ${ }^{[22,23]}$.

The IFy is a pro-inflammatory cytokine produced by T helper 1 cell (Th1). It is responsible for cell-mediated immunity. It was not well studied before. To the best of our knowledge, this study included the largest sample in breast cancer.

IFY level was inversely correlated to the nodal status $(P=0.01)$ and the staging $(P=0.02)$. This was in agreement with Zhu et al. (2013) investigating the cytokines as they regulate the immune function and thereby improve the treatment outcome in breast cancer patients. The ratio of IFY/IL6 was in node negative patients compared to the positive ones $(P=0.012)$. This was associated with lower stage $(P=0.068)$ and was reflected by better treatment outcome and improved survival[9].

New studies treating patients with IFy along with chemotherapy resulted in longer disease-free survival. There is an ongoing trial with paclitaxel, trastuzumab, and pertuzumab in Her2/neu-positive patients. Data are not yet available ${ }^{24]}$.

IFY is related to the activation of the immune system. This is the hypothesis that was investigated in breast cancer clinical trials where immunotherapy was added to chemotherapy and target therapy. It was also added 
Table 2: Correlation between IL6, IF , and clinico-pathological characteristics.

\begin{tabular}{|c|c|c|c|c|c|c|}
\hline & \multicolumn{3}{|c|}{ IL6 } & \multicolumn{3}{|c|}{ IF } \\
\hline & $\begin{array}{c}\text { Median } \\
\pm \text { SD }\end{array}$ & $r$ & $\boldsymbol{P}$ & $\begin{array}{l}\text { Median } \\
\pm \text { SD }\end{array}$ & $r$ & $\boldsymbol{P}$ \\
\hline Total & $56.20 \pm 28.715$ & & & $76.37 \pm 41.54$ & & \\
\hline Age & $58.36 \pm 23.45$ & 0.012 & 0.934 & $81.63 \pm 37.36$ & -0.043 & 0.769 \\
\hline \multicolumn{7}{|l|}{ Tumor size } \\
\hline T1 & $11.10 \pm 20.33$ & 0.614 & 0.001 & $80.43 \pm 44.03$ & 0.07 & 0.631 \\
\hline T2 & $22.40 \pm 27.73$ & & & $76.25 \pm 36.63$ & & \\
\hline T3 & $33.20 \pm 34.06$ & & & $66.63 \pm 59.47$ & & \\
\hline T4 & $65.80 \pm 36.12$ & & & $60.13 \pm 37.41$ & & \\
\hline \multicolumn{7}{|l|}{ Nodal status } \\
\hline N1 & $20.90 \pm 28.89$ & 0.933 & $>0.0001$ & $118.15 \pm 31.07$ & -0.45 & 0.01 \\
\hline N2 & $39.14 \pm 39.36$ & & & $86.72 \pm 67.74$ & & \\
\hline N3 & $67.31 \pm 28.89$ & & & $76.37 \pm 44.46$ & & \\
\hline \multicolumn{7}{|l|}{ Metastasis } \\
\hline M1 & $56.65 \pm 33.00$ & 0.852 & 0.008 & $52.50 \pm 24.40$ & -0.172 & 0.238 \\
\hline Mo & $29.4 \pm 28.11$ & & & $81.20 \pm 42.66$ & & \\
\hline \multicolumn{7}{|l|}{ Stage } \\
\hline $\mathbf{I}$ & $4.60 \pm 30.12$ & 0.761 & $>0.0001$ & $86.00 \pm 48.57$ & -0.38 & 0.02 \\
\hline II & $14.20 \pm 28.32$ & & & $79.72 \pm 37.25$ & & \\
\hline III & $34.15 \pm 30.42$ & & & $53.08 \pm 45.21$ & & \\
\hline IV & $68.16 \pm 18.10$ & & & $52.25 \pm 26.18$ & & \\
\hline \multicolumn{7}{|c|}{ Hormonal status } \\
\hline \multicolumn{7}{|c|}{ Estrogen receptor } \\
\hline Positive & $56.75 \pm 28.36$ & 0.245 & 0.09 & $77.68 \pm 41.97$ & 0.01 & 0.945 \\
\hline Negative & $16.70 \pm 4.56$ & & & $76.18 \pm 0$ & & \\
\hline \multicolumn{7}{|c|}{ Progesterone receptor } \\
\hline Positive & $59.36 \pm 28.50$ & 0.95 & 0.517 & $81.09 \pm 42.41$ & -0.029 & 0.842 \\
\hline Negative & $40.25 \pm 44.62$ & & & $76.30 \pm 6.94$ & & \\
\hline \multicolumn{7}{|l|}{ Her 2 neu } \\
\hline Positive & $58.75 \pm 22.00$ & 0.324 & 0.07 & $76.09 \pm 37.63$ & -0.05 & 0.733 \\
\hline Negative & $47.20 \pm 29.25$ & & & $77.68 \pm 41.17$ & & \\
\hline \multicolumn{7}{|l|}{ Ki67 } \\
\hline$>20 \%$ & $62.2 \pm 29.84$ & -0.113 & 0.45 & $76.00 \pm 41.70$ & -0.157 & 0.293 \\
\hline$<20 \%$ & $49.92 \pm 27.59$ & & & $87.60 \pm 42.54$ & & \\
\hline \multicolumn{7}{|l|}{ Subtype } \\
\hline Luminal A & $62.20 \pm 27.54$ & 0.19 & 0.06 & $87.60 \pm 45.92$ & -0.099 & 0.498 \\
\hline Luminal B & $55.20 \pm 30.49$ & & & $76.37 \pm 42.29$ & & \\
\hline Her 2 neu enriched & $58.75 \pm 25.22$ & & & $76.09 \pm 25.58$ & & \\
\hline \multicolumn{7}{|c|}{ Body mass index } \\
\hline Normal & $38.95 \pm 38.73$ & 0.39 & 0.05 & $69.21 \pm 60.60$ & -0.044 & 0.766 \\
\hline Overweight & $55.20 \pm 14.29$ & & & $96.88 \pm 24.62$ & & \\
\hline Obese & $69.05 \pm 29.46$ & & & $76.27 \pm 42.17$ & & \\
\hline
\end{tabular}

in other types of cancer such as colon, ovary, and glioblastoma $^{[24,25]}$.

IFY treatment in HER2 breast cancer in mice has shown a synergistic effect when combined with target therapy and immunotherapy, so when combined with anti-HER2 neu and anti-PDL 1, the response to therapy is improved ${ }^{[26]}$.

IFY was not associated with any molecular subtype $(P=0.498)$. Moreover, it was not affected by the body mass index of the patients $(P=0.766)$. This is in accordance to a recent study showing that ER positive is associated with IFY if it is signaling with $\triangle 133 T P 53$ RNA in mutant TP53 (mTP53) and ER negative if IFY is signaling TP63 RNA in wild-type TP53 (wtTP53) . IFY was associated with central obesity in normal female ${ }^{[27}$, 28].

\section{Study limitation}

The sample size of the patients was small and requires longer follow-up. 


\section{Conclusion}

IL6 level was correlated to the initial staging of the patients. This includes the tumor size, lymph node status, and metastasis. It was also related to hormonal status, Her2 positive, and obesity. The IFy level was inversely correlated to the lymph nodal status and initial staging. The levels of IL6 and IFY were inversely correlated together regarding the nodal status $(P=0.05)$.

\section{Authorship}

All authors have conceived and designed the study, collected the data, and participated in drafting and approval of the final version of the manuscript.

\section{Acknowledgment}

We are so grateful to the patients accepting to participate in this study. Our great gratitude is to our medical colleagues and cancer registry employees for helping us to collect the cases as well as the medical data.

We are deeply indebted to Cairo University in Egypt for supplying us with this fund.

\section{Potential conflict of interest}

\section{References}

[1] Siegel RL, Miller KD. and JemalA. Cancer statistics, 2016. CA: A Cancer Journal for Clinicians,2016; 66: 7-30. doi:10.3322/caac.21332.

[2] MorigiC.Highlightsfromthe15thStGallenInternational Breast Cancer Conference 15-18 March, 2017, Vienna: tailored treatments for patients with early breast cancer. ecancermedicalscience.2017;11:732. doi:10.3332/ecancer.2017.732.

[3] Divella R, De Luca R, Abbate I, Naglieri E, Daniele A. Obesity and cancer: the role of adipose tissue and adipo-cytokines-induced chronic inflammation. J Cancer 2016; 7(15):2346-2359.

[4] Ravishankaran, P., \& Karunanithi, R. Clinical significance of preoperative serum interleukin-6 and C-reactive protein level in breast cancer patients. World Journal of Surgical Oncology,2011; 9, 18. http://doi.org/10.1186/14777819-9-18.
There is no conflict of interest.

\section{Source of funding}

Fund from Cairo University in Egypt.

\section{Ethical statement}

The study was approved by the Ethical Committee of Kasr Al Ainy Medical School, Cairo, Egypt. All patients have signed an informed consent, and the work was in accordance with the Helsinki Declaration of 1975.

[5] Wang, H., \& Yang, X. Association between serum cytokines and progression of breast cancer in Chinese population. Medicine, 2017;96(49),e8840. http://doi.org/10.1097/MD.0000000000008840

[6] Ibrahim S, El-Ghonaimy E, Hassan H, Mahana N, Mahmoud M, TahaniEl-Mamlouk T, El-Shinawi M, .Mohamed M. Hormonal-receptor positive breast cancer: IL-6 augments invasion and lymph node metastasis via stimulating cathepsin B expression. Journal of Advanced Research, 2016; Volume 7, Issue 5, September, Pages 661-670.

[7] Abana $\mathrm{CO}$, Bingham BS, Cho JH, et al. IL-6 variant is associated with metastasis in breast cancer patients. Coleman WB, ed. PLoS ONE. 2017;12(7):e0181725. doi:10.1371/journal.pone.0181725.

[8] Hartman ZC', Poage GM, den Hollander P, Tsimelzon A, Hill J, Panupinthu N, Zhang Y, Mazumdar A, Hilsenbeck SG, Mills GB, Brown 
$\mathrm{PH}$. Growth of triple-negative breast cancer cells relies upon coordinate autocrine expression of the proinflammatory cytokines IL-6 and IL-8. Cancer Res. 2013; Jun 1;73(11):3470-80. doi: 10.1158/00085472.CAN-12-4524-T. Epub 2013 Apr 30.

[9] Xin Zhu, Lingbin Du, Jianguo Feng, et al . Clinicopathological and Prognostic Significance of Serum Cytokine Levels in Breast Cancer. Clinical laboratory, 2013; 60(7):1145-51.

[10] Mandai M, Hamanishi J, Abiko K, Matsumura N, Baba T, Konishi I. Dual Faces of IFNy in Cancer Progression: A Role of PD-L1 Induction in the Determination of Pro- and Antitumor Immunity. Clin Cancer Res, 2016; 22(10); 2329-34.

[11] Mostafa AA, Codner D, Hirasawa K, et al. Activation of ERa Signaling Differentially Modulates IFN-Y Induced HLA-Class II Expression in Breast Cancer Cells. Kovats S, ed. PLoS ONE. 2014;9(1):e87377. doi:10.1371/journal.pone.0087377.

[12] Marie-Emmanuelle Legrier, et al 2016. Activation of IFN/STAT1 signalling predicts response to chemotherapy in oestrogen receptor-negative breast cancer. British Journal of cancer Cancer volume114, pages 177-187.

[13] NCD Risk Factor Collaboration (NCD-RisC), Rising rural body-mass index is the main driver of the global obesity epidemic in adults. Nature. 2019 May;569(7755):260-264. doi: 10.1038/s41586019-1171-x. Epub 2019 May 8.

[14] Gyamfi J, Eom M, Koo JS, Choi J. Multifaceted Roles of Interleukin-6 in Adipocyte-Breast Cancer Cell Interaction. Transl Oncol. ;11(2):275-285. doi:10.1016/j.tranon.2017.12.009

[15] Bowers LW, Brenner AJ, Hursting SD, Tekmal RR, deGraffenried LA. Obesity-associated systemic interleukin-6 promotes pre-adipocyte aromatase expression via increased breast cancer cell prostaglandin E2 production.Breast Cancer Res Treat. 2015;149(1):49-57. doi:10.1007/s10549014-3223-0

[16] Bougaret L, Delort L, Billard H, et al. Adipocyte/ breast cancer cell crosstalk in obesity interferes with the anti-proliferative efficacy of tamoxifen. PLoS One;2018; 13 (2): e0191571. doi:10.1371/journal. pone.0191571.

[17] Modified from Schnitt SJ. Will molecular classification replace traditional breast pathology? Int J Surg Pathol. 2010;18:162S-166S. http://dx.doi.org/10.1177/1066896910370771.

[18] Correa Geyer F, Reis-Filho JS. Microarray-based gene expression profiling as a clinical tool for breast cancer management: are we there yet? Int
J Surg Pathol. 2009;17:285-302. http://dx.doi. org/10.1177/1066896908328577.

[19] El Saeed GK, Hosny Abou-elela DM, Ahmed El-Gendy MT. Evaluation of interleukin-6 and C-reactive protein in patients with breast cancer at Menoufia University Hospitals. Menoufia Med J 2016;29:337-40

[20] Noman AS, Uddin M, Chowdhury AA, Nayeem MJ, Raihan Z et al., Serum sonic hedgehog (SHH) and interleukin-(IL-6) as dual prognostic biomarkers in progressive metastatic breast cancer. Sci Rep. 2017 May 11;7(1):1796. doi: 10.1038/s41598017-01268-4.

[21] Huang WC, Hung CM, Wei CT, et al. Interleukin-6 expression contributes to lapatinib resistance through maintenance of stemness property in HER2-positive breast cancer cells. Oncotarget, 2016; 7 (38): 62352-62363. doi: 10.18632/ oncotarget 11471.

[22] Vaysse C, Lømo J, Garred O, Fjeldheim F, Lofteroed T, Schlichting E, McTiernan A, et al. Inflammation of mammary adipose tissue occurs in overweight and obese patients exhibiting earlystage breast cancer. npj Breast Cancer, 2017; 3, Article number: 19 (2017).

[23] Faria SS, Corrêa LH, Heyn GS, de Sant'Ana LP, Almeida RDN, Magalhães KG. Obesity and Breast Cancer: The Role of Crown-Like Structures in Breast Adipose Tissue in Tumor Progression, Prognosis, and Therapy. J Breast Cancer, 2020; May; 23(3):233-245. doi: 10.4048/jbc.2020.23.e35. PMID: 32595986; PMCID: PMC7311368.

[24] $\mathrm{Ni} \mathrm{L,} \mathrm{Lu} \mathrm{J.} \mathrm{Interferon} \mathrm{gamma} \mathrm{in} \mathrm{cancer}$ immunotherapy. Cancer Med.2018; 7(9):45094516. doi: 10.1002/cam4.1700. Epub $2018 \mathrm{Jul}$ 23. PubMed PMID: 30039553; PubMed Central PMCID: PMC6143921.

[25] Mojic M, Takeda K, Hayakawa Y. The Dark Side of IFN-Y: Its Role in Promoting Cancer Immunoevasion. Int J Mol Sci. 2017;19(1):89. Published 2017 Dec 28. doi:10.3390/ijms19010089.

[26] Nagai $Y$, Tsuchiya H, Ji MQ, Zhang H, Greene MI. Synergistic effect of IFN-Y on breast cancer targeted therapy. The Journal of Immunology, 2017; May , 198 (1 Supplement) 141.14

[27] Schmidt FM, Weschenfelder J, Sander C, et al. Inflammatory cytokines in general and central obesity and modulating effects of physical activity. PLoS One. 2015; 10(3):e0121971. Published 2015 Mar 17. doi:10.1371/journal.pone.0121971

[28] Mehta SY, Morten BC, Antony J, et al. Regulation of the interferon-gamma (IFN-Y) pathway by p63 
and $\triangle 133 p 53$ isoform in different breast cancer subtypes. Oncotarget. 2018; 9(49):29146-29161.

doi:10.18632/oncotarget.25635 